\title{
Community-responsive adaptation to flooding in Kibera, Kenya
}

1 Joe Mulligan CEng, MICE, ACGI, LEED AP BD+C Associate Director, Kounkuey Design Initiative, Stockholm, Sweden (corresponding author: joe@kounkuey.org)

2 Jamilla Harper MA

Associate Director for Kenya, Kounkuey Design Initiative, Nairobi, Kenya
3 Pascal Kipkemboi

Field Associate, Kounkuey Design Initiative, Nairobi, Kenya

4 Bukonola Ngobi MA

Urban Design Coordinator, Kounkuey Design Initiative, Nairobi, Kenya

5 Anna Collins BEng (Hons)

Volunteer Engineer, Engineers without Borders UK, London, UK; Civil Engineer, Arup, London, UK
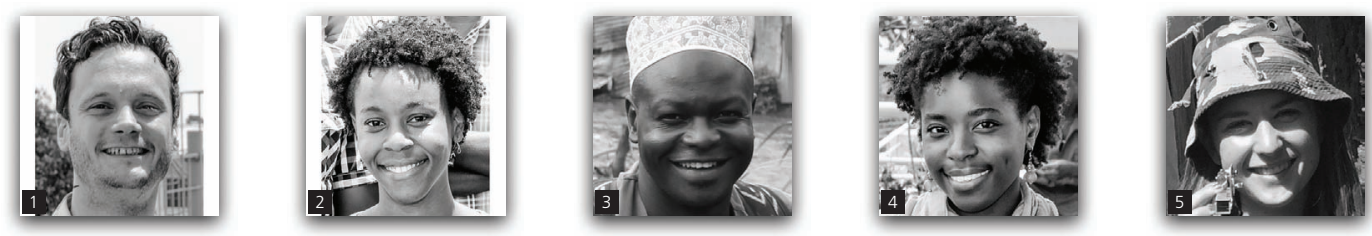

Much of the world's existing and future population will live in slums, where the twin trajectories of rapid urbanisation and increased flooding driven by climate change collide. Few spatial planning policies currently address this issue in practice. Poorly planned relocation from slum areas has caused conflict and insecurity, while large-scale infrastructural solutions for reducing flood risk are prohibitively expensive. There is a need to consider how local adaptation measures for increasing resilience to flooding can complement other structural and policy measures. This paper describes and evaluates autonomous, market-based and public-policy-driven structural and non-structural adaptation approaches to flooding in Kibera, the largest informal settlement in Nairobi, Kenya. The analysis employs a novel survey data set from 963 households in Kibera and extensive community and institutional stakeholder consultation. Results of the consultation demonstrate how autonomous adaptation at the household level is disincentivised by insecure housing tenure, while public-policy-driven approaches are constrained by the lack of effective community engagement. Combining the lessons from this analysis with 10 years of experience in developing public space and infrastructure projects in Kibera, the paper builds the case for an approach to 'community-responsive adaptation' to urban flooding that negotiates these limitations.

\section{Introduction: climate risk and adaptation in poor urban areas}

Poor urban areas are consistently located along natural drainage paths and high flood-risk areas in rapidly urbanising cities (Parikh et al., 2012). As urbanisation continues apace and uncertainty in rainfall events driven by climate change increases, a growing proportion of the economies and populations of those cities and countries will be placed at risk (Bicknell et al., 2009; Jha et al., 2012). Although the context in each settlement varies, the fundamental challenges of informal housing encroaching on flood zones and the lack of an implementable spatial planning policy to address the issue are consistent in many.

The informal settlements of Nairobi are consistently located on the city's major watercourses (see Figure 1). Kibera, Nairobi's largest informal settlement, is subject to significant flood risk due to poor drainage and its location adjacent to the Ngong River, with over
$50 \%$ of residents (from a 963 household panel survey) reporting their houses flooded in the 2015 March-April-May 'long' rains.

While the risks from climate change are greater in developing countries than in developed countries, the potential benefits from good adaptation can also be greater (Ranger and GarbettShiels, 2011). While flooding is one specific climate risk in Kibera, it also ties to a much broader set of vulnerability issues (waterborne disease, public health, livelihoods, urban fragility). Local 'no-regret' adaptation measures therefore have the potential to significantly increase resilience in the longer term, along with or independent of other structural and policy measures.

To consider which adaptation measures have the potential to build resilience in Kibera and other informal settings, this paper uses evidence from Kibera to compare the prevalence and 


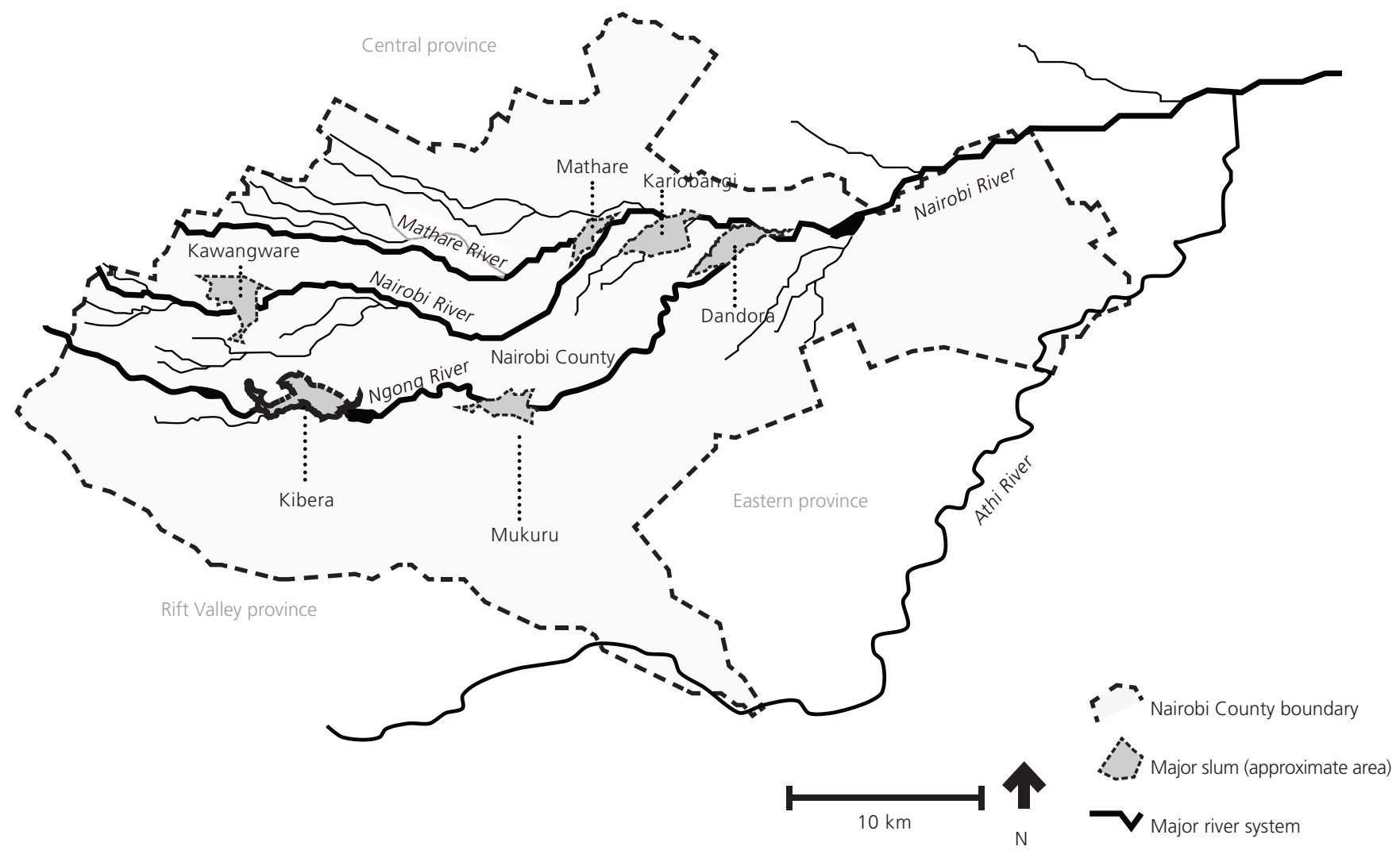

Figure 1. The major waterways and informal settlements of Nairobi County. Graphic: Jessica Bremner and Joe Mulligan (KDI)

sustainability of autonomous, market-based and public-policydriven adaptation approaches to flooding. The paper then develops a case for a 'community-responsive adaptation' that navigates the current limitations of autonomous and public-policydriven approaches. Special consideration is given to considering lessons for the scaling of adaptation approaches and addressing government engagement in integrated planning. The paper draws on the practice and research of the design and community development organisation Kounkuey Design Initiative (KDI) in two areas: (a) novel quantitative and qualitative research on impacts and responses to urban flooding in Kibera, from research funded by the Swiss Re Foundation and carried out by KDI in 2015; (b) learning from 10 years of building public space projects in Kibera that address multiple climate and environmental risks to build social and economic resilience.

\section{Urban flooding in Kibera}

\subsection{Climate risk in Kibera}

Kibera, the most populous informal settlement in Nairobi, covers 225 ha adjacent to the Ngong River and its tributaries and has a population of approximately 300000 (UN-Habitat, 2006). The residents of Kibera face many challenges, including high levels of economic poverty, high rates of crime and unemployment, and insufficient water and sanitation infrastructure.
The Ngong River, on which Kibera lies, is one of three major river systems in the Nairobi River basin, with an upstream catchment of 6000 ha. It is estimated that at least 30000 Kibera residents live within $30 \mathrm{~m}$ of the main watercourses. Immediately downstream of Kibera lies the Nairobi dam, and $5 \mathrm{~km}$ further, Nairobi's central business district. Organic pollution levels driven by the unchecked disposal of solid and human waste from the settlement can be at the level of raw sewage (NRBP, 2008).

Urban climate threats currently facing Kibera are severe. Every year, residents in Kibera face the risk of flooding, which causes disease, death and destruction of property. Rents are often cheaper along rivers and streams, where flood risk is higher, attracting the poorest and most vulnerable residents who are willing to risk their lives and assets to stay in the city. The localised flooding of pathways and drainage systems is aggravated by the high level of impervious roofing and the erasure of natural water retention and filtration zones by human settlement (Meso, 2013) as well as the unchecked disposal of solid waste into the watercourses. Bridges, access ways and other essential infrastructure located in the flood zones are often dangerous and impassable during heavy rains.

In the medium term, these risks are set to increase, driven in large part by ongoing rapid urbanisation. Nairobi's urban population is projected to double by 2025 (KNBS, 2008), with the majority of 
Community-responsive adaptation to

flooding in Kibera, Kenya

Mulligan, Harper, Kipkemboi, Ngobi and Collins the new arrivals expected to be housed in informal settlements. Flood risk in Kibera is projected to increase due to a combination of continued densification in both the formal and the informal city, riparian encroachment and reduction of pervious surfaces in Kibera and upstream.

In the longer term, flood risks are also expected to increase under climate change scenarios. Although the rate of change is still uncertain, almost all results for East Africa point to an increase in mean precipitation rates and intensity of high-rainfall events (Cook and Vizy, 2013; Shongwe et al., 2011), increasing the likelihood of flash flooding and overloading of drainage systems, which are characteristic of urban flood risk.

\subsection{Assessing the impacts of flooding in Kibera}

In March and June of 2015, a panel survey of 963 households pre- and post- the long rains was delivered by KDI in Kibera. The March 2015 survey established a baseline of household demographics, assets, vulnerability, perception of risk and historical experience of flooding, while the June post-rains followup focused on the actual damages/impacts incurred during the March-April-May 2015 long rains.

The study areas for the household survey were selected based on an initial scoping and comparison of potential study areas in January 2015, using criteria adapted from Abarquez and Murshed (2004), including perception of the severity of community's exposure to flood/other risks. All areas of Kibera experience localised surface water flooding due to poor drainage, while some experience riverine flooding. Five study areas were selected in the survey; four areas included zones with exposure to riverine flooding, and one area was on higher ground with no exposure to riverine flooding. Figure 2 shows a map of the Kibera settlement, locations of the household survey, indicative areas of riverine flooding and locations of KDI's completed Kibera Public Space Project (KPSP) sites.

Within the study areas, the households were selected using a two-stage procedure. Firstly, all compounds were identified from a geographic information system map of the structures in Kibera within each study area. Second, a census of households within a random sample of the compounds was conducted and a proportion of those households were selected for interview. The sampling procedure was designed to approximate random sampling in the context of an urban informal settlement without reliable census data to use as a sampling frame.

The survey follows standard protocols for research with human subjects. The chieftaincy and other authorities were informed of the consultation, and the subjects gave oral consent to be interviewed. The subjects received a written summary of the study and key contacts. Oral consent was used as many participants had limited literacy. Survey participants were compensated for the time required to participate in the survey with a small incentive consisting of a bar of antibacterial soap. Data were collected using the Open Data Kit platform on Android smartphones, and the data

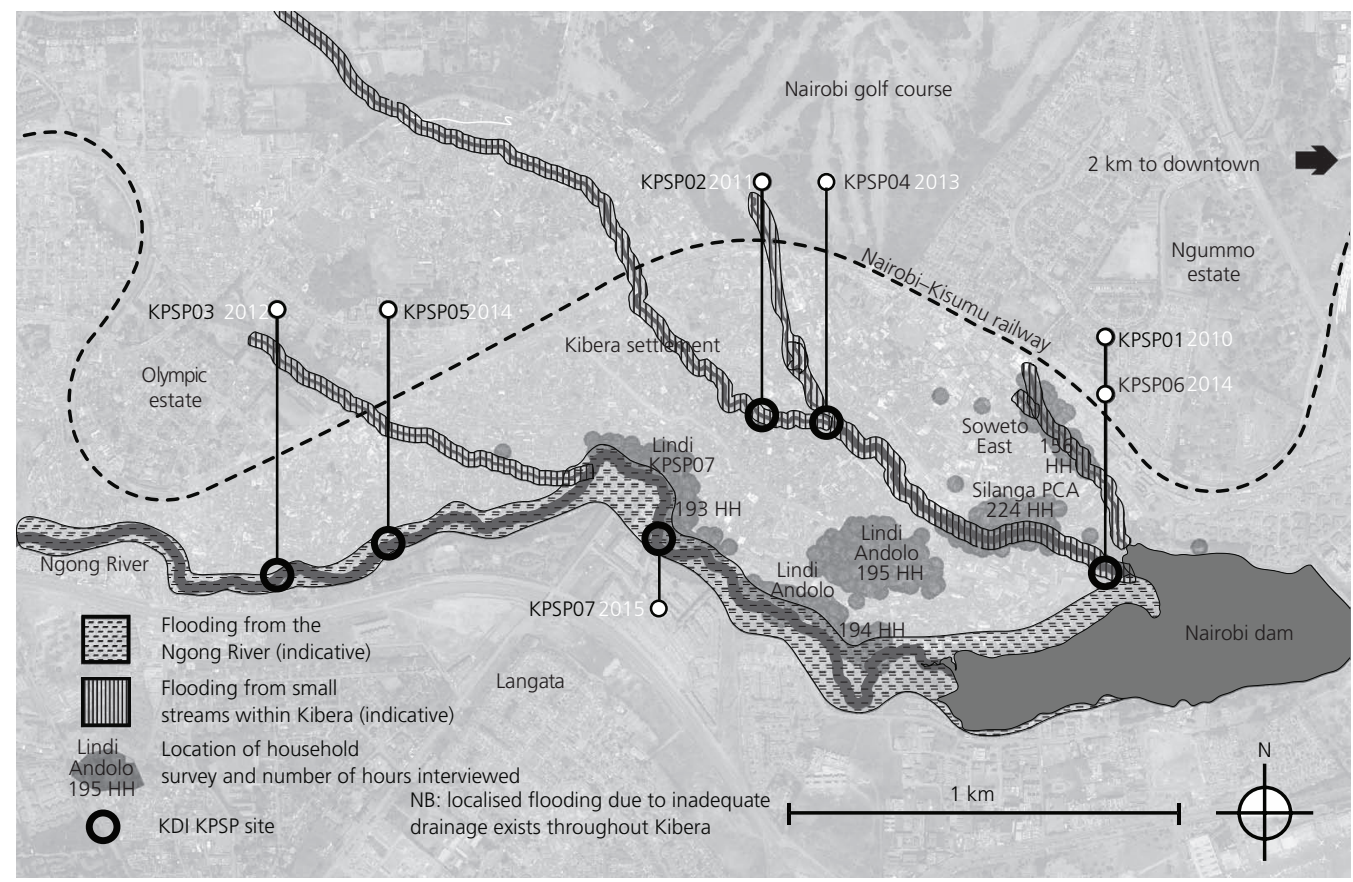

Figure 2. Map of the Kibera settlement, locations of household surveys, indicative locations of riverine flooding and location of KDI KPSP sites 
Engineering Sustainability

Volume 170 Issue ES5
Community-responsive adaptation to

flooding in Kibera, Kenya

Mulligan, Harper, Kipkemboi, Ngobi and Collins were uploaded to a secure server. Full details on the consultation methodology are presented in a paper by Mulligan (2015).

At follow-up, the KDI field team completed a full household survey in $85 \%$ of the study households ( 822 households). Eleven per cent of the households from the original survey had moved, despite the short period between survey rounds ( $8-10$ weeks). The field team interviewed these households by phone; $34 \%$ of the households that had moved ( 37 households) moved because of flooding. Across all respondents in the survey, the team interviewed 903 of the original 963 respondents, achieving an overall response rate of $94 \%$.

\subsection{Overview of the impacts of flooding in Kibera}

Initial results from the household survey showed a high proportion of households reporting flooding (defined here as water entering the household by walls or doors). $40 \%$ of the households interviewed reported flooding of their dwellings in the 12 months prior to March 2015, while over 50\% interviewed in June reported flooding of their dwellings in the long rains of March-April-May 2015. There were 112 households that relocated in this period, of which 37 households relocated because of flooding. The increase in reported flooding compared with the previous year may reflect the heavy rains of 12 May 2015, when Nairobi received up to $116 \mathrm{~mm}$ of rain in $1 \mathrm{~d}$ (recorded at Dagoretti Corner on 12 May 2015) (KMD, 2015), causing widespread flooding, damage and loss of life. Figure 3 shows flood damage in Kibera after the heavy rains.

The study documents significant consequences for public health. From the post-rains survey, $10 \%$ of households reported deaths caused by flooding in their communities, although a lack of an official death toll makes the number of people killed by flooding hard to estimate. $60 \%$ of the residents interviewed reported

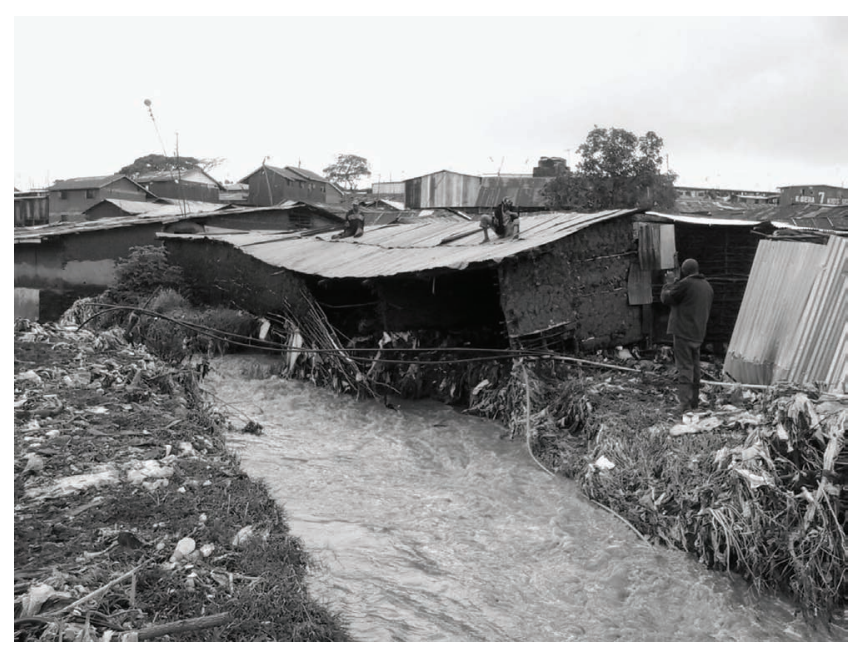

Figure 3. High waters and flood damage on the Ngong River in the Andolo area of Kibera after heavy rains on 12 May 2015. Photograph by Pascal Kipkemboi (KDI) outbreaks of cholera in their community, with 20 respondents reporting cases in their own households. Across all study areas, 31\% of children were reported to have had diarrhoea within the last 2 weeks, more than double the national urban average (14.3\%) (KNBS, 2015). Diarrhoeal disease is one of the leading causes of death among children under 5 years old in slums (Kyobutungi et al., 2008).

Further impacts extended to household assets, livelihoods and security. $36 \%$ of all households reported their structures damaged, while more than half reported some assets damaged or ruined. Of the $67 \%$ of respondents earning an income, over $72 \%$ reported that flooding had impacted their ability to get to their place of work.

The impact of localised flooding (due to poor local drainage and solid waste management) throughout the settlement is of particular note with residents living outside the immediate riverine flood zone reporting a consistently high level of household flooding and diarrhoeal disease. The majority of flooding in the long rains of 2015 was reported to emanate from internal compound drainage (38\%), with drainage flooding from outside the compound accounting for $26 \%$ and just $16 \%$ from the river itself (the remainder recorded as roof leakage).

Qualitative information from focus group discussions undertaken in the same study areas as the household surveys showed that women are typically the first responders, removing children from danger, bailing out houses and compounds, and making sure sick children and elderly family members get treatment.

\subsection{Policy and institutional context in Kibera}

Relatively little work has been done on the potential impacts of climate change on urban settlements in low-income nations or on how to mainstream adaptation to climate change into policy or infrastructure planning (Muller, 2007). A consistent challenge across the board is that community perspectives have rarely been integrated into planning processes (Baker, 2012). In Kenya, this lack of context has led to an over-reliance on poorly planned relocation. The existing national policy (chapter 372 of Water Act 2002 (National Council for Law Reporting, 2012)) designates a 6-30 m riparian zone within which all permanent structures are deemed illegal (Dadu, 2010). In 2009, the National Environmental Management Authority (Nema) estimated that implementing the policy would require the eviction of 137000 people along the Mathare, Nairobi and Ngong Rivers at a cost of US\$18 million (Nation, 2009). The policy was described by Amnesty International as 'socially and economically disastrous for thousands of people' (AI, 2009: p. 21) and has proved unenforceable, creating tensions between residents and implementing agencies and resulting in significant protest.

A series of key informant interviews (KIIs) was undertaken by KDI in 2015 with senior institutional figures at local, county and national levels, including the Kenya Meteorological Department, the 
Water Resources Management Authority, Nema, the Ministry of Water and Irrigation and the National Disaster Operations Centre, among others. The interviews demonstrated a clear gap between the scale of the issue and the current knowledge and capacity to respond within governmental and non-governmental organisations. While a commitment to the Hyogo Framework and intention to implement the incoming Sendai Framework exists on paper, the coordination and resources required have not been mobilised. Kenya has a draft national disaster management policy awaiting cabinet approval that clarifies how the system works at national and county scales, but it is less clear how disaster risk reduction can be practically devolved to the sub-county and community scales. National level policy guidance places an emphasis on large rural catchments (Ministry of Water and Irrigation, 2009) with little consideration of a smaller catchment such as the Nairobi River basin, despite the significant populations placed at risk from nuisance and more serious flooding. The application of disaster risk reduction measures in the slum context is further complicated by the issue of land, the political and financial costs of relocation and the lack of consultation and legitimacy in target communities. The report Unjust Waters by ActionAid (2006: p. 18) highlights challenges identified in 2006 that remain to date.

Steps are needed to create awareness and build capacity within the [Nairobi] city council for the application of the [Hyogo] framework and other relevant protocols and conventions for the needs of the urban poor.

The lack of coordination between governmental agencies compounds the risk of climate-related threats in the short and longer terms. To date, governmental responses, particularly in the informal context, have been limited and retroactive. Only six (out of 963) of the residents interviewed in the 2015 pre-rains survey reported any engagement in local authority exercises related to flooding preparation or response. In focus group discussions with community groups in flood-affected areas, the only organisations credited with any disaster response were the Kenyan Red Cross, Amref Health Africa and Médecins Sans Frontières, demonstrating how disaster preparedness and emergency response remain the domain of humanitarian agencies.

\section{Adaptation measures in Kibera}

\subsection{What is sustainable adaptation in the context of "slums"?}

'Sustainable adaptation' can be seen as part of a broader family of approaches seeking to combine the objectives of climate change adaptation and poverty alleviation (Brown, 2011). It can mean different things in different contexts, especially given that adaptation and poverty are complex, multi-dimensional and dynamic concepts themselves (Brown, 2011). While flooding is a specific climate risk, it also ties to a much broader set of vulnerability issues (waterborne disease, public health, livelihoods, urban fragility), so adaptation measures to address flooding have the potential to impact on longer term poverty reduction.
Discussing which adaptation measures are 'sustainable' is particularly challenging in the context of Kibera and other informal settlements due to the unresolved status of land and housing rights and is connected to the lack of effective government engagement. Tanner and Mitchell (2008) argued that certain 'autonomous adaptation' strategies for coping with climate risk among the extremely poor can actually increase vulnerability and therefore cannot be considered sustainable. It could be argued that adaptation measures that are undertaken in the context of current inadequate housing and services serve to reinforce an unsustainable system. In considering the sustainability or not of current and potential adaptation measures in Kibera, two extra dimensions to conventional adaptation approaches suggested by Brown (2011) should be kept in mind. Firstly, the measure should actively reduce poverty and/or vulnerability and, secondly, it must ensure that actions are sustainable in the long term and do not undermine resilience (Brown, 2011).

\subsection{Flood adaptation measures in Kibera}

Adaptation is often presented as a series of planned and discrete interventions initiated from outside organisations or by governments. However, more commonly, individuals and households undertake spontaneous incremental and continuous adaptation, integrated with and balanced against other livelihood adjustments in the face of multiple stressors (Brown, 2011; Leichenko and O'Brien, 2008). This is indeed the case in Kibera, where measures to reduce local risk to flooding are often taken at the household level (rented by individuals or families), the compound level (clusters of households usually managed by a 'landlord') and the community level (community-based organisations or traditional hierarchies present in the settlement). Community-level adaptation may be supported internally or by outside sources - that is, governmental, non-governmental or multi-lateral agencies. Adaptation at the scale of the settlement or larger watershed requires governmental coordination at county and national levels.

A qualitative assessment of the prevalence (or existence) of a broad range of structural and non-structural adaptation responses to flood risk in Kibera at the various scales described earlier is given in Figure 4. The assessment is designed to give an overview of the current status of adaptation measures and is based on extensive quantitative and qualitative data from

- KDI household survey data, as introduced in Section 2.2

- a series of focus group discussions in March and April 2015 in each of the survey areas based on the communitybased disaster risk management model (as described in Abarquez and Murshed, 2004; Arup, 2011; Shaw and Okazaki, 2003)

- transit walks and observational photograph surveys undertaken by KDI and Engineers without Borders UK documenting local adaptation measures in September 2015

- a series of three flood awareness and preparation days with residents in September 2015. 
Engineering Sustainability

Volume 170 Issue ES5
Community-responsive adaptation to

flooding in Kibera, Kenya

Mulligan, Harper, Kipkemboi, Ngobi and Collins

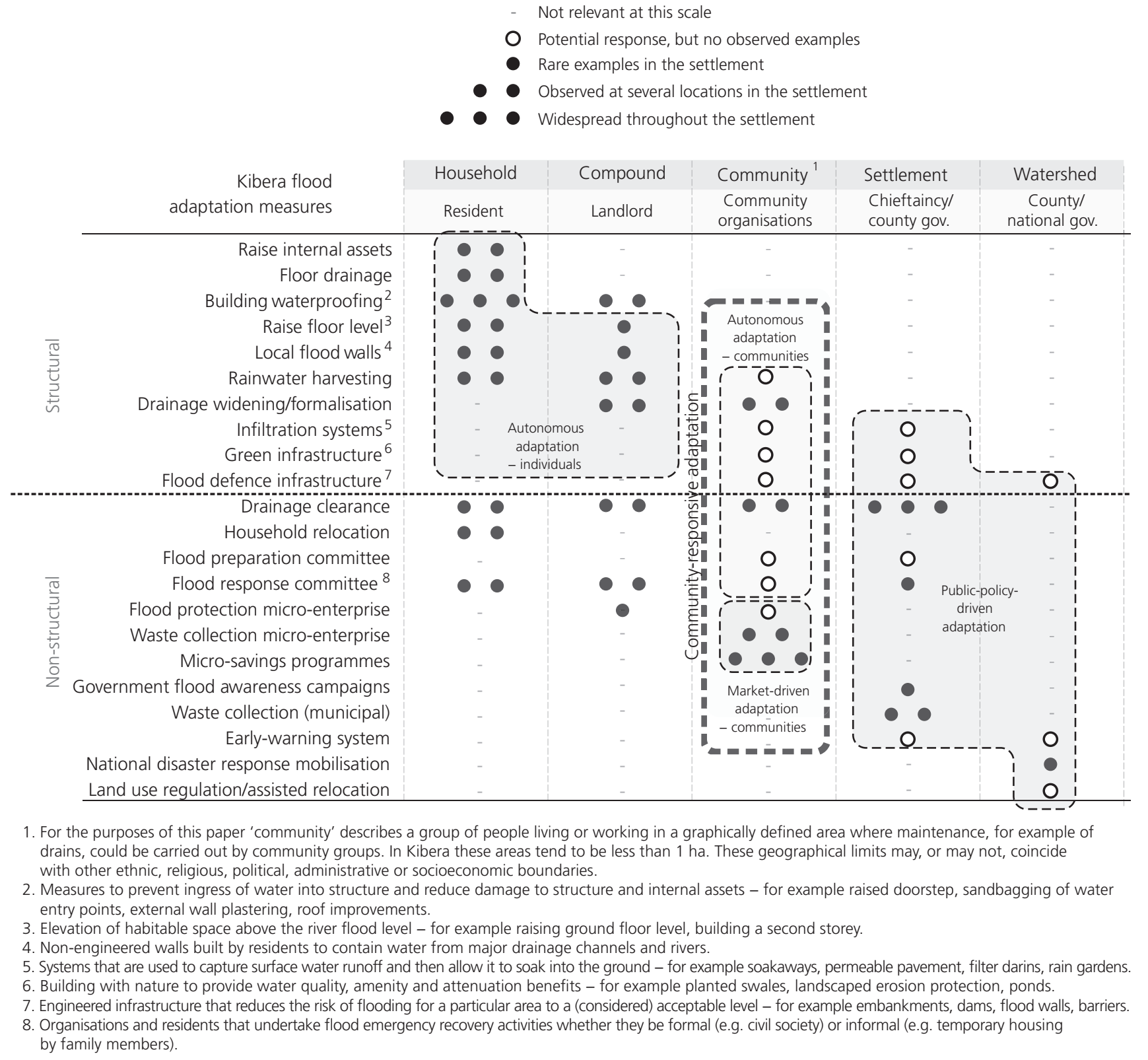

Not relevant at this scale

- Rare examples in the settlement

- Observed at several locations in the settlement

Widespread throughout the settlement

Figure 4. Qualitative assessment of the prevalence of structural and non-structural adaptation measures to flooding at various scales in Kibera

When following the definitions used by Tanner and Mitchell (2008), clear groupings emerge between autonomous adaptation (i.e. that initiated by residents and community groups), marketbased adaptation (characterised in Kibera by micro-finance and micro-enterprises also initiated at the community level) and public-policy adaptation (government driven).

The analysis shows the relative prevalence of autonomous measures at the household and community levels, as well as the importance of small financing schemes. In addition, income- generating activities that can contribute to adaptation are common and have the potential to provide multiple benefits - for example solid waste collection. The lack of implementation of government-driven adaption measures in the informal settlements is seen as a result of the lack of a public-policy framework directly addressing these areas and the pushback against historical attempts to enforce relocation from the riparian zone. Further discussion and evidence from Kibera under each of these three groupings, as well as a discussion of the sustainability of each, is given in the following sections. 
Engineering Sustainability

Volume 170 Issue ES5
Community-responsive adaptation to

flooding in Kibera, Kenya

Mulligan, Harper, Kipkemboi, Ngobi and Collins

\subsubsection{Autonomous adaptation in Kibera}

Incremental adaptation measures recorded in Kibera through household surveys are often structural and low cost: $30 \%$ of houses had an upstand on the doorway and $25 \%$ had improved drainage in and around the household. A smaller percentage included more expensive measures such as waterproofing of building walls (11\%) and raised foundation levels (13\%). Of these structural renovations, $41 \%$ were pre-existing, while the remainder $(59 \%)$ had been implemented by the current occupant.

At the compound or community level, $27 \%$ of households reported taking part in local grading to improve drainage, $46 \%$ in drainage clearance, $11 \%$ in drainage expansion and $12 \%$ in improving the flood worthiness of compound roofs. Larger scale projects, such as building river walls, was reported by only $1 \%$ of respondents (11 households). The majority of these practices were reported to take part in the rainy season $(61 \%)$ as opposed to the

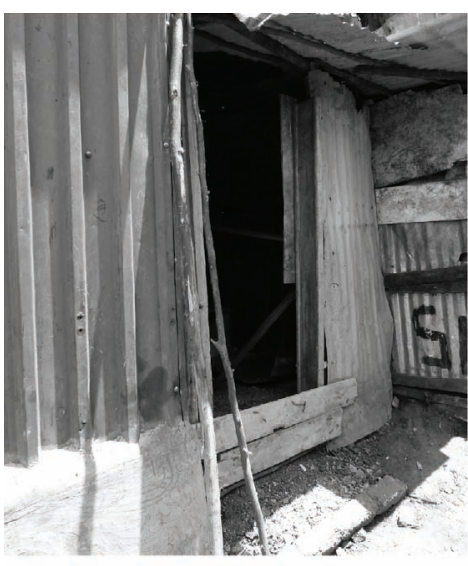

(a)

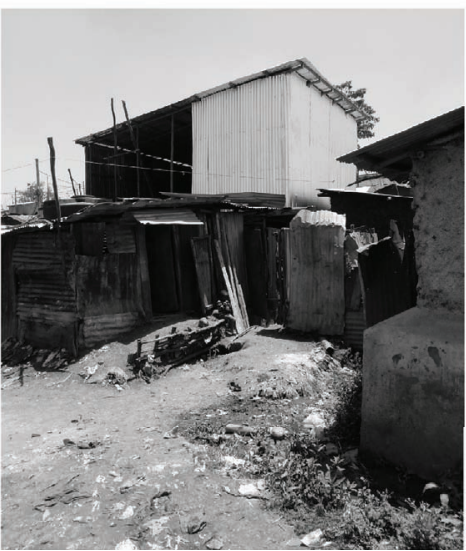

(c)

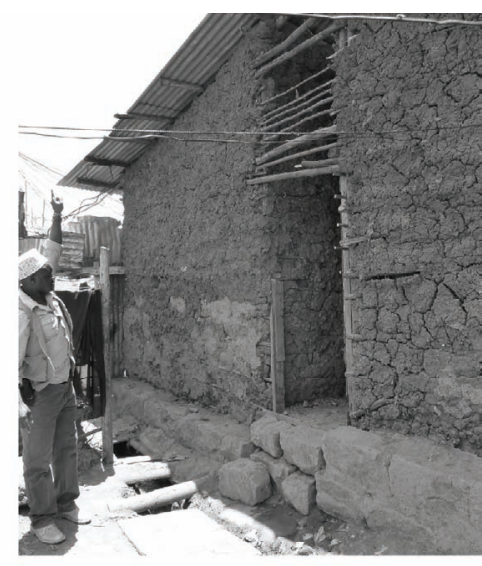

(b)

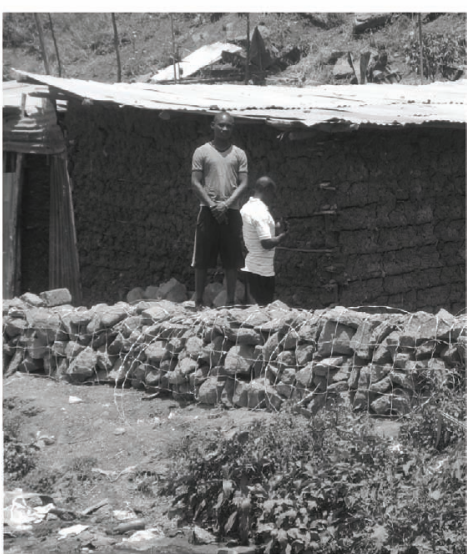

(d)
Figure 5. Examples of autonomous adaptation measures at household and community scales in Kibera: (a) doorstep for stopping water ingress, Andolo area, Kibera; (b) local flood wall and raised building foundation, Andolo area, Kibera; (c) double- dry season (39\%), suggesting they could be reactive in large part. Photographic examples of a number of these adaptation measures at household, compound and community levels are shown in Figure 5 .

While some of these short-term adaptation measures might be classified as 'coping', any investment in physical adaptation can also be seen to reduce vulnerability to the impacts of climate change by increasing the immediate safety of individuals in the short term and by reducing exposure to public health issues (i.e. repeated bouts of diarrhoea or cholera) that have the potential to undermine community resilience in the longer term. At the same time, the effectiveness of autonomous adaptation is limited if the quality is poor. In the authors' observations, there were numerous examples of adaptation measures that were poorly constructed and washed away. Residents tend to mimic what they see other households or communities implementing, but there are few 
Engineering Sustainability

Volume 170 Issue ES5
Community-responsive adaptation to

flooding in Kibera, Kenya

Mulligan, Harper, Kipkemboi, Ngobi and Collins examples of good autonomous adaptations, which further strengthens the case for properly informed and designed measures.

Despite the potential of autonomous adaptation to reduce local risk, there are significant disincentives to both individuals (renters) and landlords/structure owners to invest in quality adaptation beyond small fixes. Addressing the underlying issues of insecure housing tenure is critical to enabling investment in sustainable adaptation that goes beyond low-cost and reactive coping measures. Landlords/structure owners are not subject to any regulatory requirements to provide a certain level of service to renters, and renters correspondingly do not have incentives to invest significantly in a structure that they neither own nor have the security of long-term rental tenure. These tensions were repeatedly raised by residents during focus group discussions and during information sessions on local structural adaptation measures run by KDI in 2015 and are reflected in the relatively low numbers of households reporting undertaking even minor structural renovations to houses that year.

\subsubsection{Market-driven adaptation in Kibera}

Residents have taken to market-driven approaches, such as micro-finance and savings and loans groups, in significant numbers. For example, the household surveys showed that $13 \%$ of residents were part of a formal savings group. While these strategies have limited impact on physical risk reduction directly, they do improve their financial capacity to cope with shocks. This mechanism is particularly important in a context where $86 \%$ of those flooded in the year preceding March 2015 reported receiving no support. Only one household reported being supported by the local government ('the chieftaincy'), the rest relying on family and local community support structures. In the absence of more formal financial services, these savings and loan groups provide an important service and can build social and economic resilience.

Another market-driven small business that has adaptation implications is solid waste management. Household collection and disposal is a common business among youth groups who collect a small fee from each house. Research by KDI shows there were 21 such groups operating in Kibera as of early 2015. This is a response to a market gap in a settlement where municipal solid waste services were non-existent until very recently. Despite performing an important service, many of these businesses have only exacerbated environmental and flood risk by disposing of collected waste in drainages or in the river itself, in the absence of any real alternatives. Recent government initiatives to create municipal waste collection points throughout the settlement have the potential to make this practice a central plank in reducing flood risk and ultimately adaptation, as well as a continued source of income for entrepreneurial youth. In addition, there is at least one example of a local 'fundi' (skilled craftsperson) being hired by landlords to build local community flood-protection measures - a potential model for 'flood-protection micro-enterprises' to spread low-cost and effective structural adaptations.

These measures correspond to some of the low-cost/highrobustness 'social resilience' approaches identified in the comparison of Ranger and Garbett-Shiels (2011) of the robustness

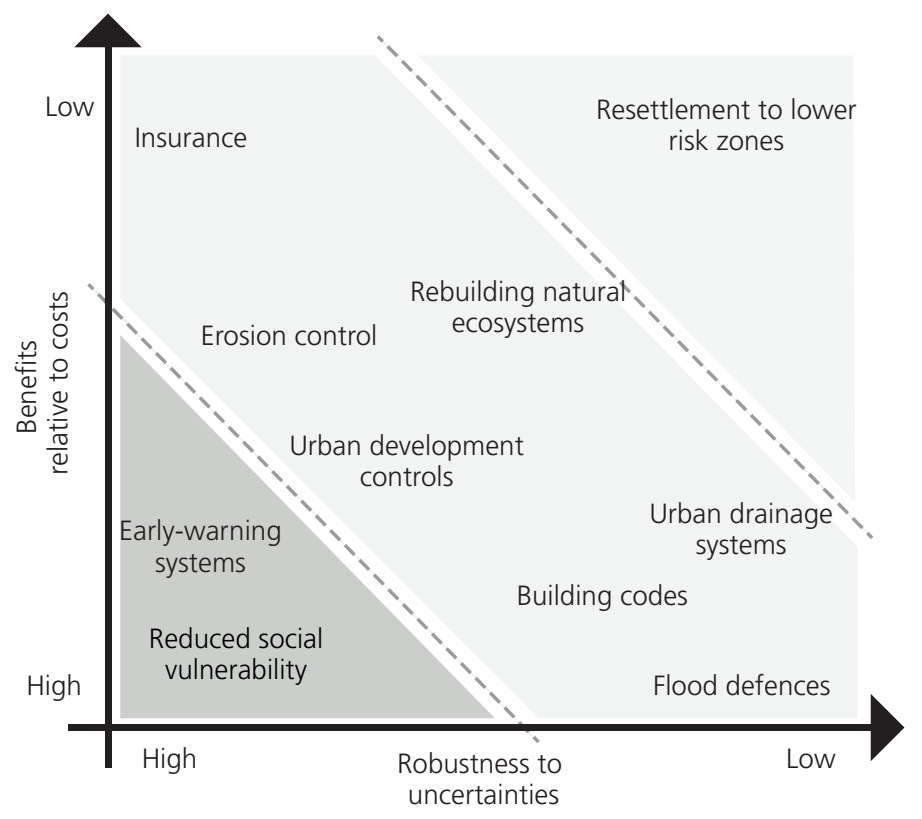

Figure 6. Comparison of the robustness of structural and non-structural measures to reduce flood risk to climate change uncertainties (adapted from Ranger and Garbett-Shiels, 2011) 
of structural and non-structural measures to reduce flood risk to climate change uncertainties (see Figure 6).

\subsubsection{Public-policy-driven adaptation in Kibera}

The lack of penetration of climate change and adaptation thinking in public policy means that measures by government to address directly flood risk in Kibera (and indeed in the wider Nairobi) have been limited. Localised river remediation and adaptation projects have been carried out at the small scale by governmental and non-governmental parties in Nairobi; however, they have not been carried out with a holistic understanding of flood risk, housing or land, impacts on residents or cost. Ngobi et al. (2015) give a full summary of initiatives in this area.

A critical sticking point consistently raised by governmental stakeholders is the challenge of moving residents and structures from high-exposure areas. The blanket riparian-zone policy in Kenya has proved unenforceable and unaffordable in Kibera and the wider informal context. Having a more nuanced understanding of flood extents and housing patterns would allow for more responsive and cost-effective plans for adaptation interventions and rehousing where necessary, and was identified as a clear information gap by a number of institutional stakeholders during KIIs in 2015.

One recent county government initiative of note directly related to flood-risk reduction at the Kibera settlement scale (and subsequently of relevance downstream also) has been drainage clearance. Blocked drainage was considered one of the main culprits of the flooding in May 2015 (Chege, 2015), and action in this area has taken on a new urgency in the run-up to the October short rains. It should be noted that these activities are limited to short-term risk reduction and do not consider longer term upgrading, formalising of drainage or water detention/infiltration.

In the background, major government infrastructure projects currently taking place in the settlement (including new roads, water and sewerage trunk lines, city-connected ablution blocks and municipal waste collection stations implemented by the Ministry of Devolution and Planning and the National Youth Service) have the potential to reduce poverty significantly. While a debate exists on whether to distinguish between adaptationspecific activities and 'normal' development (Muller, 2007), it is clear that these projects have the potential to provide basic services, improve environmental conditions and support economic development, potentially reducing vulnerability significantly. The relative success of these projects $(89 \%$ of household survey respondents were 'in support' of these recent government initiatives) is highly significant in the historical context of limited investment in infrastructure in the settlement over many decades, particularly considering a number of previous large-scale projects that have stalled due to resistance from residents. These major projects can also enable community-scale projects that now have the potential to connect into formal systems (particularly new municipal water and sewerage trunk lines), lessening the gap between formal and informal cities.
Since investment in large water management infrastructure has a potential design life of more than 100 years, the interventions of today may well be operating under the climates of the twenty second century (Muller, 2007). Unfortunately, these large infrastructure projects in Nairobi and Kenya have often missed opportunities to develop more integrated solutions that could also address current and future climate risks. An example is the excavation and installation of a new collector sewerage trunk line by the government and the Athi Water Services Board in 2014 and 2015 , which cleared the riparian zone of informal structures for large stretches of the Ngong River (approximately $2 \mathrm{~km}$ ). Despite the illegality of building in the flood zone, the informal structures returned (often on top of the sewer line and its manholes) once the sewerage was completed (see Figure 7). This was tacitly allowed to expedite the project by avoiding the thorny issue of housing and relocation, trading off the opportunity to protect people in these high-exposure areas and to improve the environmental conditions in the river. This highlights the missed opportunity in this specific case to build in climate resilience into infrastructure planning in an integrated and potentially transformative way.

\section{Principles of 'community-responsive adaptation' and considerations for further work}

\subsection{Principles of sustainable community-responsive adaptation}

From the analysis of adaptation at various scales in Kibera, the sustainability challenges of local-scale autonomous adaptation and public-policy-driven approaches are clear. The first suffers from financial and legal disincentives and a potential lack of long-term viability; the second has failed to respond to the needs and priorities of residents and/or does not explicitly incorporate a consideration of current climate risk and future climate change. At the same time, the research and experiences to date have demonstrated that residents have sophisticated knowledge on responses to short-term climate risks and also what needs to exist for a more sustainable adaptation.

As a response, the authors propose that a set of autonomous and local physical adaptation measures at the community scale, which also enable market-driven adaptation, have the potential to constitute a community-responsive model of sustainable adaptation in the informal context. The approach corresponds to a grouping of measures identified in Figure 4 that combine autonomous and market-based structural and non-structural adaptation measures at the community scale.

Principles of community-responsive adaptation are given in Figure 8 and present some guidance on how to approach projects in the context of Kibera and other settlements facing related challenges.

The potential of solutions at this scale is reaffirmed by the experiences of KDI in delivering local resilience projects in 
Engineering Sustainability

Volume 170 Issue ES5
Community-responsive adaptation to

flooding in Kibera, Kenya

Mulligan, Harper, Kipkemboi, Ngobi and Collins

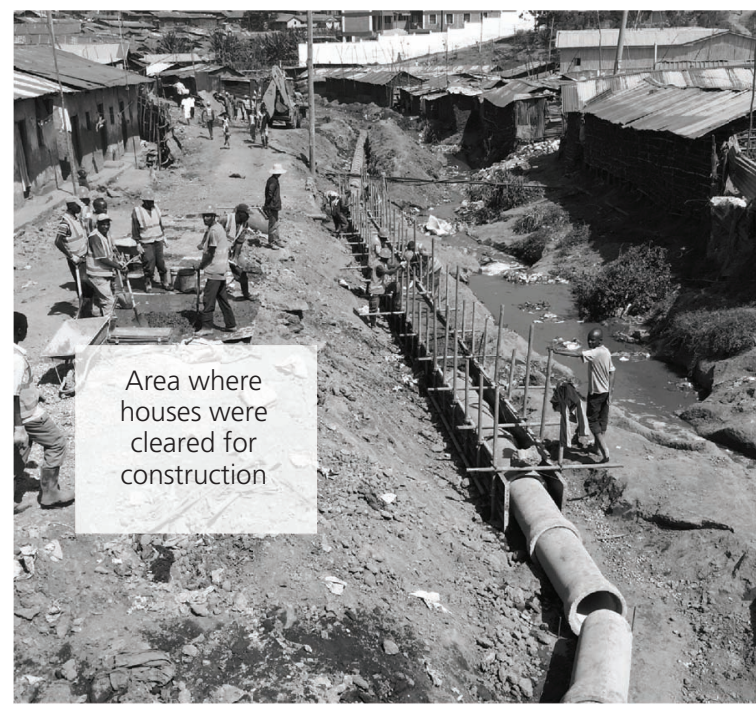

(a)

Figure 7. Government sewerage and housing encroachment in the riparian zone, Kisumu Ndogu village, Kibera. (a) Government sewerage project under construction on 17 January 2015 in the riparian zone on tributary to the Ngong River in the Kisumu Ndogu village in western Kibera. Multiple structures were cleared

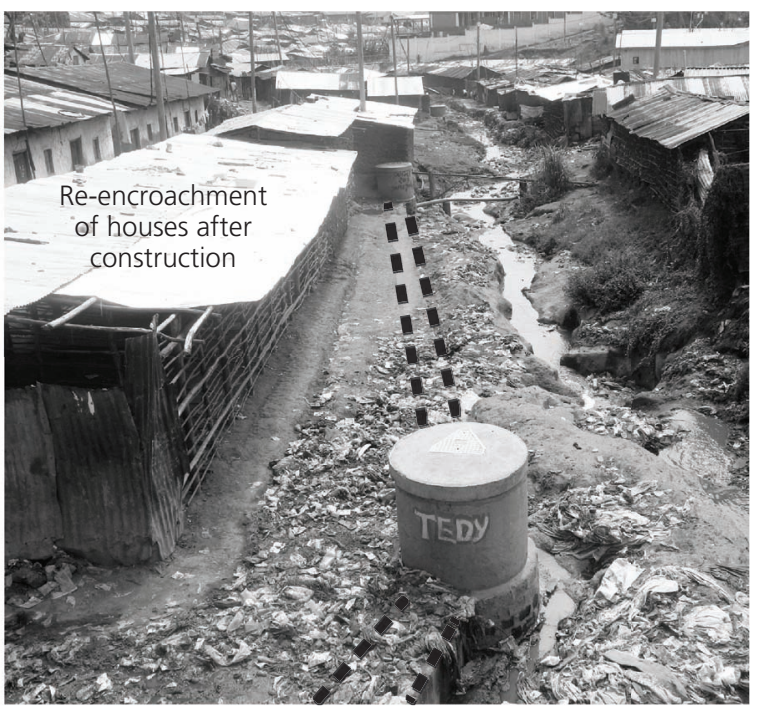

(b)

for the sewerage construction. Photograph: Joe Mulligan (KDI). (b) Completed government sewerage project in same location on 21 October 2015. Significant reconstruction of houses has taken place in the riparian zone. Photograph: Pascal Kipkemboi (KDI)
Kibera over 10 years that tailor soft and hard solutions in response to the specific conditions of place and people. Critically, the measures include physical adaptations that communities are already demonstrating and could also be implemented with support from a responsive and engaged government (public policy) agenda and/or with non-governmental and multi-lateral agencies who have the technical expertise, access to resources and holistic approach to make these options more effective and viable.

\subsection{Implementing community-responsive adaptation}

In the Kibera context, both governmental and non-governmental bodies are a long way from being able to design and deliver integrated projects of the type suggested. Bodies such as the Urban Rivers Rehabilitation Program support communityresponsive solutions; however, robust evidence on the design, implementation and cost of community-responsive adaptation measures is limited.

Projects such as the KPSP provide important evidence on how to engage communities in integrated projects that not only reduce climate risks but also build resilience. By targeting rivers, providing flood protection, building sanitation centres and supporting door-to-door trash collection programmes, the projects attempt to reduce pollution of the larger watershed (see Figure 9). The projects have demonstrated that resident-led adaptation to climate and environmental risk can also generate ongoing social and economic benefits. More broadly, they have initiated a discussion about connecting these local improvements to the rest of the region while providing concrete, practical examples of how to achieve lofty municipal and ministerial goals, such as the restoration of the Nairobi dam and the Nairobi River basin.

\subsection{Adaptation at settlement and watershed scales: addressing government engagement}

One small-scale community project in Kibera, no matter how nuanced or layered, cannot solve its own problems that expand beyond the neighbourhood (Hou and Yocom, 2015). Despite the challenges of top-down approaches in the informal context, the main avenue for scaling of the elements of the communityresponsive approach described here, for Kibera and for other contexts, should be by way of governmental partners. Many of the critical issues at hand in the context of informal settlements (water, sewerage, drainage, solid waste and access) need physically networked infrastructure. There is an opportunity to integrate and layer these networked infrastructures adjacent to the rivers and tributaries of the settlement to support access, public space, river remediation and basic services to the urban poor (Parikh et al., 2012). This idea, related to practices such as 'slum networking', aims to solve problems of flooding for the city as a whole while providing services for slum dwellers in lowlying areas adjacent to natural drainage paths (Parikh et al., 2012).

Sustainable adaptation projects driven by government for informal settlements such as Kibera will, however, require a step change in government approach at local and national levels, both 
Community-responsive adaptation to

flooding in Kibera, Kenya

Mulligan, Harper, Kipkemboi, Ngobi and Collins
Principles of community-responsive adaptation people

People

- Vulnerable people are best placed to understand the specific challenges they face in the areas they live; therefore, they must be involved in identifying solutions

- As first responders and agents of change in the settlement, women should play a central role in initiatives to improve preparedness and response, as well as in growing resilience in the longer term

- Flood impacts extend beyond river and drainage flood zones to affect public health and well being of all residents

- Integrated adaptation solutions that consider flood protection water, sanitation, public space and income-generating activities can transform the physical, social and economic resilience of communities

Place

- Effective action for climate change adaptation needs to be specific to the context at a local (sub-catchment) scale as climate risks vary significantly from one area to the next

- Improving physical flood protection and drainage in both areas adjacent to the river and to minor drainage ways within the settlement is a critical solution for reducing the direct and indirect risks of flooding

- Hard (structural) adaptation solutions need to be complemented by soft (non-structural) solutions to achieve cost-effectiveness and sustainability (e.g. ongoing revenues and maintenance arrangements)

- Landscape-driven approaches to physical flood protection and drainage can be cost-efficient, can restore ecological functions and can be flexible to climate change

- By improving the physical and environmental quality of the spaces, conflict and tensions are reduced and communities are inspired to collaborate and take pride in maintaining their surroundings

- Public space can be a focal point through which many of these structural and non-structural solutions merge to address the confluence of flooding, poor drainage, solid waste dumping and lack of sanitation in slums adjacent to rivers

Scale

- Micro-scale improvements of physical and social resilience not only reduce climate risk in and of themselves but can also secure and amplify the effects of larger infrastructural interventions (i.e. by plugging into formal government infrastructure)

- Reliable information on flood exposure and settlement patterns is required to enable the planning for integrated adaptation solutions at micro-scale and settlement scale

Figure 8. Principles of community-responsive adaptation

in developing public-policy vehicles for climate change and adaptation thinking and in meaningful engagement with the communities most impacted. It has been noted that financing participation (on top of the capital costs of infrastructure) is a significant constraint on the types of integrated projects described here. Future research could provide data on the process and costs of a more engaged participation with residents on adaptation measures to support decision-making and budget planning for both governments and non-governmental practitioners.

Although challenges and missed opportunities exist in Nairobi, there is a growing level of interest and engagement in the issues of flooding, climate and appropriate policy responses, as demonstrated by recent initiatives such as the Nairobi River Basin Programme, the Urban Rivers Rehabilitation Programme and the Taskforce for the Rehabilitation of the Nairobi Dam (Ngobi et al., 2015). The severe flooding of May 2015 and the current El Niño period have sharpened governmental mobilisation, and the recent devolution of power to the county level puts Nairobi in a favourable position to drive collaboration across relevant departments.

\subsection{Conclusions and next steps}

To address the need for detailed information at the settlement scale, flood-risk mapping for Kibera is currently being undertaken by KDI and Buro Happold Engineering's water team in Bath, UK, by using remote and field-collected data, as well as vulnerability and risk information from the household survey conducted in 2015, and will be tested in partnership with government partners in 2016. The mapping will show flood risk and also settlement patterns, local drainage, topography and the location of municipal infrastructure. This mapping will hence enable community-level adaptation to take advantage of municipal infrastructure (e.g. by taking solid waste collected from drainage to a central collection point or by connecting a new ablution block to the municipal sewer).

From the governmental perspective, it is hoped that a flood-risk map for Kibera, grounded in up-to-date community information, will enable a more nuanced understanding of risk and the actual needs for high-cost resettlement against other adaptation measures and a step towards an alternative to large-scale displacement. This paper includes only initial results from the household surveys undertaken in 2015, but it is expected that this new body of knowledge will add significantly to current data in this area and support government and non-governmental programmes in Kibera and other slums.

Overall, the research has demonstrated that residents have sophisticated knowledge about the consequences of climate change, how to act quickly and effectively to respond to shortterm climate risks and also the priorities for longer term adaptation. As Kibera residents continue to come together to cope with and adapt to increasing flood risk, there is some hope that the government will step up its efforts and coordination to develop integrated responses to the real challenges of its citizens.

\section{Acknowledgements}

The authors thank the Swiss Re Foundation for their continued support of KDI and for funding the research on which this paper is partly based. Deepest thanks and respect are given to the KDI Kenya office, in particular to Jamilla Harper, Pascal Kipkemboi, 
1. Existing condition: Kibera hotspot

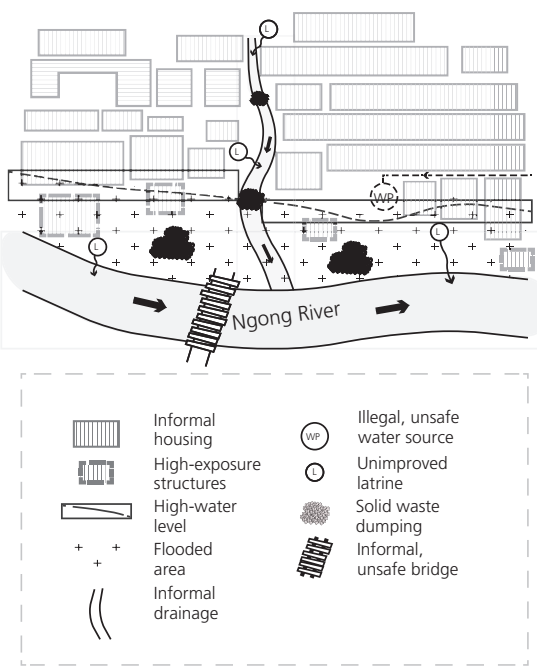

2. Public space and integrated water management

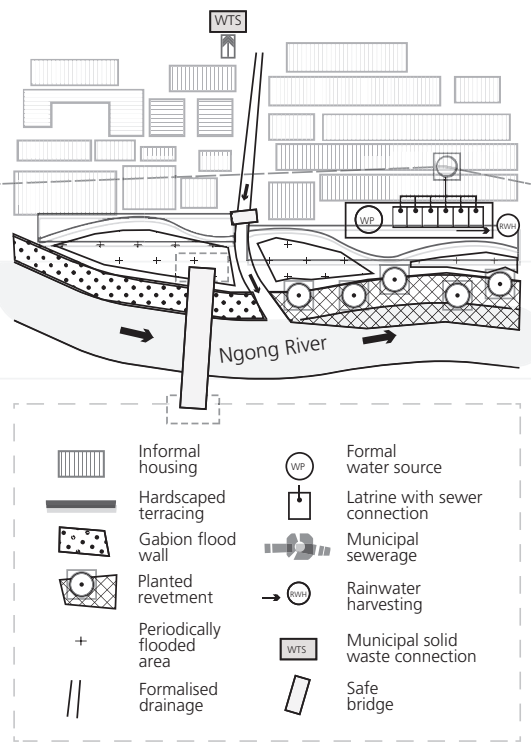

3. KDI KPSPO7

(under construction March 2016)

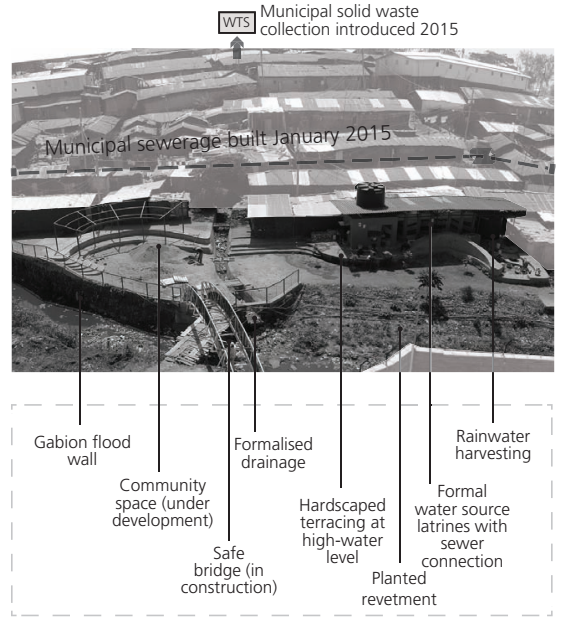

Figure 9. KPSP integrated approach to river remediation and flood protection (using example of current project under construction, KPSP07). Graphic: Joe Mulligan (KDI); photograph: Pascal Kipkemboi, KDI field associate

Amos Wandera and Ibrahim Maina for leading the data collection and analysis in the most challenging of environments. Special thanks are given to Buro Happold Engineering's water team in Bath (Alan Travers, Duncan Ker-Reid, Nilani Venn and Rodoloua Gregoriou) for continued support of KDI's Urban Flooding programme. Many thanks are also given to International Alert's Environment, Climate Change and Security team (Janani Vivekananda, Shreya Mitra and Dr Janpeter Schilling) for their fellowship and review of material related to this paper. Huge appreciation is given to Engineers without Borders UK for providing fundamental and ongoing volunteer support to the Urban Flooding programme. Thanks are given to Chelina Odbert, executive director of KDI, for her commitment and belief in the fundamental importance of grounded community work. Lastly, special thanks are given to Dr Anna Tompsett of Stockholm University for her support of the survey design and review and suggestions on this paper.

\section{REFERENCES}

Abarquez I and Murshed Z (2004) Community-Based Disaster Risk Management: Field Practitioners' Handbook. The Asian Disaster Preparedness Center, Pathumtani, Thailand. See http:// www.adpc.net/v2007/programs/CBDRM/Publications/ Downloads/Publications/12Handbk.pdf (accessed 31/05/2016). ActionAid (2006) Unjust Waters: Climate Change, Flooding and the Protection of Poor Urban Communities: Experiences from Six African Cities. Action Aid International, Johannesburg, South Africa.
Al (Amnesty International) (2009) Kenya: the Unseen Majority: Nairobi's Two Million Slum-Dwellers. Amnesty International, London, UK, AFR 32/005/2009.

Arup (2011) Characteristics of a Safe and Resilient Community Community Based Disaster Risk Reduction Study. Arup International Development, London, UK.

Baker J (2012) Climate Change, Disaster Risk, and the Urban Poor-Cities Building Resilience for a Changing World. World Bank, Washington, DC, USA.

Bicknell J, Dodman D and Satterthwaite D (2009) Adapting Cities to Climate Change: Understanding and Addressing the Development Challenges. Earthscan, London, UK.

Brown K (2011) Sustainable adaptation: an oxymoron? Climate and Development 3(1): 21-31, http://dx.doi.org/10.3763/cdev. 2010.0062 .

Chege N (2015) Why floods won't go away in Nairobi. Nairobi News, 8 June. See http://nairobinews.nation.co.ke/why-floodswont-go-away-in-nairobi/ (accessed 10/09/2015).

Cook KH and Vizy EK (2013) Projected changes in East African rainy seasons. Climate 26(16): 5931-5948, http://dx.doi.org/ 10.1175/JCLI-D-12-00455.1.

Dadu KC (2010) A negotiated framework for rehabilitation of riparian zones in Nairobi City: the case of Mathare River Valley (Kenya). Case study presented on the ISOCARP Congress 2010: Sustainable City - Developing World.

Hou J, Spencer B, Way T and Yocom K (2015) Now urbanism: the future city is here. In The Kibera Public Space Project: 
Community-responsive adaptation to

flooding in Kibera, Kenya

Mulligan, Harper, Kipkemboi, Ngobi and Collins
Participation, Integration and Networked Change (Odbert C and Mulligan J (eds)). Routledge, London, UK, pp. 177-192. Jha AK, Bloch R and Lamond J (2012) Cities and Flooding: A Guide to Integrated Urban Flood Risk Management for the 21st Century. World Bank, Washington, DC, USA.

KMD (Kenya Meteorological Department) (2015) 2015 Daily Rainfall Data from Weather Station Rainfall Gauges at Wilson Airport and Dagoretti Corner. KMD, Nairobi, Kenya.

KNBS (Kenya National Bureau of Statistics) (2008) Kenya National Bureau of Statistics Population Projection. KNBS, Nairobi, Kenya. See http://www.knbs.or.ke/ (accessed 19/05/ 2016).

KNBS (2015) Kenya Demographic and Health Survey 2014. KNBS, Nairobi, Kenya.

Kyobutungi C, Ziraba AK, Ezeh A and Yé Y (2008) The burden of disease profile of residents of Nairobi's slums: results from a demographics surveillance system. Population Health Metrics 6(1), http://dx.doi.org/10.1186/1478-7954-6-1.

Leichenko RM and O'Brien KL (2008) Environmental Change and Globalisation: Double Exposures. Oxford University Press, Oxford, UK.

Meso J (2013) Space contestation in the Riparian zone of Nairobi CBD, Ngara section, Planning Research Project, University of Nairobi. See http://www.academia.edu/4219098/Space_ Contestation_in_the_Riparian_Zone_of_Nairobi_CBD_ Ngara_Section.

Ministry of Water and Irrigation (2009) Flood Mitigation Strategy, June 2009.

Muller M (2007) Adapting to climate change: water management for urban resilience. Environment and Urbanization 19(1): 99-113, http://dx.doi.org/10.1177/0956247807076726.

Mulligan J (2015) Consultation and Data Collection Methodology for the Building Urban Flood Resilience in Kibera Project. Kounkuey Design Initiative, Los Angeles, CA, USA. See http://www.kounkuey.org/150323\%20KDI\%20Urban \%20Flooding\%20Consultation\%20and\%20Data\%20Collection \%20Methodology\%20REV01.pdf (accessed 19/05/2016).

Nation (2009) 127,000 living near Nairobi River to be moved. Daily Nation, 14 April. See http://www.nation.co.ke/News/-/ 1056/560462/-/u491jw/-/index.htm (accessed 03/03/2016).

National Council for Law Reporting (2012) Water Act 2002, chapter 372. National Council for Law Reporting, Nairobi, Kenya.

Ngobi B, Mulligan J and Odbert C (2015) Re-imagining the future waterways of Nairobi. International Federation of Landscape Architects Africa Symposium, Nairobi, Kenya.

NRBP (Nairobi River Basin Programme) (2008) Nairobi River Basin Programme Phase III: Resource Booklet on Pollution Monitoring Activities. International Union for Conservation of Nature, Network for Water and Sanitation International and UN Environment Programme, Nairobi, Kenya. See http:// www.ircwash.org/sites/default/files/Netwas-2005-Resource.pdf (accessed 31/05/2016).

Parikh P, Parikh H and McRobie A (2012) The role of infrastructure in improving human settlements. Proceedings of the Institution of
Civil Engineers - Urban Design and Planning 164(2): 61-73, http://dx.doi.org/10.1680/udap.10.00038.

Ranger N and Garbett-Shiels S (2011) How Can Decision-makers in Developing Countries Incorporate Uncertainty about Future Climate Risks into Existing Planning and Policymaking Processes? Policy Paper, The Grantham Research Institute on Climate Change and the Environment, London, UK. See http:// eprints.lse.ac.uk/39978/ (accessed 31/05/2016).

Shaw R and Okazaki K (2003) Sustainability in Grass-Roots Initiatives: Focus on Community Based Disaster Management. United Nations Centre for Regional Development Disaster Management Planning, Hyogo, Japan. See http://www.uncrd. or.jp/content/documents/143Sustainability $\% 20$ in $\% 20$ GrassRoots\%20Initiatives\%20Focus\%20on\%20Community\% 20Bases\%20Disaster\%20Management.pdf (accessed 31/05/ 2016).

Shongwe ME, van Oldenborgh GJ, van den Hurk B and van Aalst M (2011) Projected changes in mean and extreme precipitation in Africa under global warming - part II: East Africa. Journal of Climate 24: 3718-3733, http://dx.doi.org/10.1175/ 2010JCLI2883.1.

Tanner T and Mitchell T (2008) Entrenchment or enhancement: could climate change adaptation help to reduce chronic poverty? IDS Bulletin 39(4): 6-15, http://dx.doi.org/10.1111/j. 1759-5436.2008.tb00471.x.

UN-Habitat (2006) Nairobi Urban Sector Profile. UN Human Settlements Programme, Nairobi, Kenya.

\section{HOW CAN YOU CONTRIBUTE?}

To discuss this paper, please email up to 500 words to the editor at journals@ice.org.uk. Your contribution will be forwarded to the author(s) for a reply and, if considered appropriate by the editorial board, it will be published as discussion in a future issue of the journal.

Proceedings journals rely entirely on contributions from the civil engineering profession (and allied disciplines). Information about how to submit your paper online is available at www.icevirtuallibrary.com/page/authors, where you will also find detailed author guidelines. 